\section{All that tics may not be Tourette's}

SIR: Gilles de la Tourette syndrome (GTS) is characterised by multiple motor and one or more vocal tics lasting more than a year. Transient tic disorder (TTD) represents tics of duration less than a year, while in chronic multiple tics (CMT) they (vocal or motor) have been present for more than a year (American Psychiatric Association, 1987).

The hereditary nature of the syndrome was recognised by Gilles de la Tourette himself. There are still controversies about the possible phenotypes of the putative GTS gene(s), whether all cases of tics represent the GTS clinical spectrum, and what proportion of patients with tics have a disorder genetically related to GTS.

Family studies have reported that TTD and CMT are aetiologically related to GTS (Kurlan et al, 1988). While GTS is probably the most common cause of tics, they may also be due to other causes. Clinically the distinction between 'GTS tics' and other forms of tics is difficult. Some of these may represent habits, mannerisms, or physiological tics. GTS tics characteristically have a waxing and waning course, are suppressible, suggestible, and exacerbated by stress. While this is useful in clinical practice, such phenotypic definitions are far from optimum for genetic and linkage studies.

Eapen et al (1993), using a 'goodness of fit test', reported that the predicted and observed frequencies of GTS were not significantly different. However, when relatives with CMT and TTD were also included as affected, the observed rates were significantly different from the expected, indicating a poor fit for the data. This suggests that not all relatives with tics have a disorder that is genetically related to GTS. In these circumstances, motor tics (chronic and transient) may be phenocopies.

Although much of the genome has been excluded (Heutink et al, 1990; Pakstis et al, 1991), this may be a reflection of incorrect definition of the phenotypes. Definitive answers to some of these questions may have to await the development of a genetic marker for the GTS gene. In the meantime, if an 'endophenotype' can be identified, this will help link the clinical phenotype (the external clinical manifestation that can be observed) with the genotype (the underlying genetic mechanism).

American Psychiatric Association (1987) Diagnostic and Statistical Manual of Mental Disorders (3rd edn, revised) (DSM-IIIR). Washington, DC: APA.

Eapen, V., Pauls, D.L. \& Robertson, M.M. (1993) Evidence for autosomal dominant transmission in Tourette's syndrome. United Kingdom cohort study. British Journal of Psychiatry. 162, 593-596.
Heutink, P., van de Wetering, B.J.M., Breedveld, G.J., et al (1990) No evidence for genetic linkage of Gilles de la Tourette syndrome on chromosomes 7 and 18. Journal of Medical Genetics, 27, 433-436.

Kurlan, R., Behr, J., Medved, L., et al (1988) Transient tic disorder and the spectrum of Tourette's syndrome. Archives of Neurology, 45, 1200-1201.

Pakstis, A.J., Heutink, P., Pauls, D.L., et al (1991) Progress in the search for genetic linkage with Tourette's syndrome: an exclusion map covering more than $50 \%$ of the autosomal genome. American Journal of Human Genetics, 48, 281-294.

\section{VALSAMma EAPEN}

MARY M. ROBERTSON

Department of Psychiatry

University College London Medical School

London WIN 8 AA

\section{Brain, mind and behaviour}

SIR: Fenwick (BJP, November 1993, 163, 565-573) has written an intriguing article on the influence of new imaging techniques in broadening our understanding of major psychiatric illnesses, and suggests that this increased knowledge of brain function will have consequences for the expert medical witness who has to give evidence in court. He suggests that in the area of diminished responsibility, the concept of the guilty mind belongs to a non-scientific era and that the subtle brain malfunction demonstrated by new neurophysiological techniques may come to assume increasing importance in matters of criminal responsibility.

In support of his theory, Fenwick describes "The Case of the Miserable Teenager", and is critical of the jury, who were not convinced by his explanation of the offence and returned a verdict of guilty to murder rather than culpable homicide on the grounds of diminished responsibility.

We believe we were among the psychiatrists for the Crown in this case, and there are certain important omissions in Fenwick's account. We are constrained in our comments by issues of ethics and confidentiality, but confining our observations solely to what is already in the public domain through the press reporting of the incident, there were components of motivation, planning and subsequent concealment which may have influenced the jury in reaching the decision it did. These aspects potentially offer a different interpretation to that put forward by Fenwick.

We feel that it is prudent to be cautious in appraising Fenwick's theory, and there should be objective scientific evaluation and independent confirmation of his propositions before neuroimaging 
begins to replace the guilty mind as the basis of responsibility.

\section{Royal Dundee Liff Hospital By Dundee DD2 5NF}

Murray Royal Hospital Perth PH2 $7 \mathrm{BH}$

\section{Cyclic psychosis, menstrual cycle and adolescence}

SIR: Stein et al (BJP, December 1993, 163, 824 828) referred to the paucity of reported cases of cyclic psychosis associated with menstruation. I would like to add two further case reports to the existing meagre pool.

Case 1. B was a 14-year-old referred urgently, having become acutely disturbed. She had menarche seven months earlier, but had seen no period subsequently. The initial symptoms were manic with loss of sleep, excess activity, pressure of talk, loosening of associations, and a belief that she had been given special discounts from a local shop, which had led her to knocking on neighbours' doors, offering to buy things for them. This picture altered within $\mathbf{4 8}$ hours, without treatment, to one of depressed mood, crying easily, sleeplessness, and a sense of anguish relating to vivid depersonalisation and derealisation phenomena. She could not tolerate her mother leaving her side. This picture lasted two more days, and resolved completely in another two days, to be followed by total remission for $\mathbf{2 2}$ days. It then recurred, lasting a further six days. On this occasion, phenothiazines were used and the overall intensity was reduced. Total remission followed again. Electroencephalography was performed twice, during the remission and during the acute phase, but proved negative.

Having been informed of the existence of previous episodes, we checked for dates with the school and it became clear, from her attendance records, that there had been in total five episodes occurring exactly every 28 days and lasting for a week on every occasion. On the basis of this information, phenothiazines were withdrawn and treatment with progestogen instituted. The patient experienced no psychotic episodes in the next six months, her periods reappeared, and the patient was discharged from clinic.

Five years later, B developed a puerperal psychosis two days after the birth of her first child. After recovery, she has remained well for the next three years, when follow-up discontinued.

Case 2. $\mathrm{C}$ was a 14-year-old girl admitted to an adolescent unit with symptoms of emotional lability, extreme clinginess, perplexity, and derealisation phenomena. There had been a spontaneous remission within 10 days, but she relapsed three months later. C's menarche had been eight months earlier, her periods were irregular, but both episodes had started two days before the onset of her period. Progesterone levels were found to be low, progestogen treatment was instituted and $C$ recovered and suffered no further relapses.

In the case reported by Stein $e t$ al and case 2 above, cyclic psychotic disturbance was associated with menstruation. In case 1 above, the psychotic episodes actually replaced the menstrual cycle. It is perhaps also remarkable that in all three cases, derealisation phenomena were present, inviting speculation that they may be the central feature of a specific syndrome.

\section{A. Ambelas}

Westcotes House

Westcotes Drive

Leicester LE3 OQU

\section{CORRIGENDUM}

BJP Supplement 22, p. 10. The legend to Fig. 1 should have given the following key: The in vivo antagonistic potencies of each compound at adrenergic $(\square)$, histamine $(\nabla)$, serotonergic $(\Xi)$ and muscarinic $(\square)$ receptors are expressed relative to its antagonistic potency at dopaminergic (III) receptors.

\section{A HUNDRED YEARS AGO}

\section{Kleptomania}

The close connexion between moral error and mental disease is a circumstance which constantly imposes upon the practitioner a difficulty of the same duplex character in relation to diagnosis. Moral alienation, it is well known, indicates from a very early stage the decay of the reasoning faculty. Moral insanity, in like manner, denotes that mental state which exhibits in its feeble and absolute submission to the senses the failure of healthy selfcontrol. Among its innumerable forms, an interest which is not entirely pathological attaches to the sometimes rather comical vice of "kleptomania". The question of criminal responsibility overshadowed by this term brings it more or less within the scope of public opinion. There are, no doubt, a number of cases which illustrate only what may 